\title{
A ciência da informação como ciência social
}

\section{C arlos Alberto Á vila A raújo}

Doutorando em ciência da informação pela ECI/UFMG

Professor licenciado das Faculdades Integradas de C aratinga-M G E-mail: casalavila@yahoo.com.br

\section{Resumo}

Discute-se a natureza da ciência da informação como uma ciência social. Para tanto, identifica-se como se deu a inserção da ciência da informação nas ciências sociais, percebendo com quais ramos destas ela travou diálogo em diferentes momentos. A seguir, discute-se sua natureza de ciência "pós-moderna", percebendo a complementaridade entre essas duas questões para um eficiente diagnóstico dos fundamentos sociais da ciência da informação.

\section{Palavras-chave}

Fundamentos sociais da informação; Ciência da informação e ciências sociais; Ciência pós-moderna.

\section{Information science as social science}

\author{
Abstract \\ This article discusses the Information Science like a social \\ science. For that, the author identifies the insertion of \\ Information Science in the social sciences, perceiving the \\ different fields in the social sciences with which Information \\ Science establishes dialogue. Next, the article discusses the \\ nature of "postmodern" science, perceiving the \\ complementarity between this two questions for a efficient \\ diagnosis of the social foundations of the Information \\ Science.
}

\section{Keywords}

Social foundations of information; Information science and social sciences; Postmodern science.

\section{IN TRO D U ÇÃ O}

A ciência da informação é tradicionalmente definida, em termos institucionais (de acordo com classificações de agências como Capes e CN Pq e divisões internas nas várias universidades), como uma "ciência social aplicada". Em várias instâncias, existe um espaço específico para a discussão da natureza social dos fenômenos informacionais (por exemplo, nas linhas de pesquisa em "Informação e Sociedade", "Informação e Cultura" ou "Ação Cultural" dos programas de pósgraduação em ciência da informação e nos grupos de trabalho com esse tema em associações e congressos como o Enancib), o que não significa, contudo, que a sua dimensão social seja negligenciada em linhas ou GTs que enfatizam outros aspectos (a questão do tratamento da informação, a questão gerencial, a interface tecnológica). Contudo, se em termos institucionais ou terminológicos parece indiscutível a natureza social da ciência da informação, em termos propriamente teóricoepistemológicos essa inserção não é exatamente óbvia.

0 objetivo deste trabalho é discutir a natureza da ciência da informação enquanto uma ciência social. Para tanto, pretende-se indicar em que momento, desde seu surgimento, a ciência da informação buscou aproximarse e constituir-se como uma ciência social e, nesse movimento de aproximação, com qual manifestação das ciências sociais a ciência da informação teve maior identidade, tomando de empréstimos conceitos, teorias e metodologias de pesquisa.

Sem entrar aqui na discussão sobre as relações entre a ciência da informação e outros campos do conhecimento como a biblioteconomia e a documentação (Dias, 2002), pode-se dizer que é consenso entre os autores da área que a ciência da informação surge em meados do século XX. De acordo com Pinheiro \& Loureiro (1995), em 1948 , a obra de $N$ orbert W iener, Cybernetics or control and communication in the animal and machine, e, no ano seguinte, o livro Themathematical theory of communication, de Claude Shannon e W arren W eaver, marcam 0 prenúncio do que viria a ser a ciência da informação. A inda de acordo com os autores, data de 1959 o primeiro uso do termo e "é na década de 60 que são elaborados os primeiros conceitos e definições e se inicia o debate sobre a origem e os fundamentos teóricos da nova área" (Pinheiro \& Loureiro, 1995, p. 42). 


\section{Carlos Alberto Ávila A raújo}

Os autores apontam vários fatos ocorridos na década de 60 que significam verdadeiros marcos da formação de um novo campo disciplinar: a conferência realizada no Georgia Institute of Technology em 1962, o Relatório W einberg em 1963, o trabal ho Informática, de M ikhailov, em 1966, o estudo de Rees e Saracevic em 1967 e, por fim, a clássica definição de B orko presenteem Information Science: what is it?, de 1968.

A ciência da informação, uma ciência, portanto, bastante recente, nasce em um período histórico em que já se observam as primeiras críticas ao fracasso do projeto da modernidade e ao modelo científico resultante desse projeto. M esmo assim, e como essa crise não está claramente delineada ainda, a ciência da informação, nesse período, constitui-se exatamente nos moldes das ciências modernas, sobretudo a partir do modelo das ciências exatas, buscando atingir um conhecimento exato - de inspiração matemática e quantitativa, à medida que o movimento da modernidade buscou "impor um finalismo matemático a todas as outras ciências" (Bronowski, 1977, p. 47) -, utilizando-se da máxima objetividade, buscando formular leis universais de "comportamento" da informação:

"Lidar com o gran de volume ea diversificação de informações registradas em variadas formas, com vistas à sua mais ampla difusão, foi o imperativo condicionante da ciência da informação. Fortemente influenciadas pelas ciências empíricas, as primeiras manifestações desse campo embrionário pretendiam estabelecer leis universais que representassem o fenômeno informacional, daí a recorrência a modelos matemáticos (teoria da informação), físicos (entropia) ou biológicos (teoria epidemiológica). (...) $\mathrm{Na}$ década de setenta, entra em cena um personagem que redireciona 0 enfoque da ciência da informação: 0 usuário. (...) Com a presença dosusuários, as ciências humanas esociais passam a contribuir também, com seus métodos e práticas, para a composição dessa ciência emergente". (Cardoso, 1996: 73-74)

Portanto, a ciência da informação não "nasce" ainda como uma ciência social. M uito ligada inicialmente à computação (como atesta, por exemplo, a importância do trabalho de $V$ annevar Bush) e à recuperação automática da informação, ela vai, apenas nos anos 70 , promover sua inscrição efetiva nas ciências sociais: "A ciência da informação recebe das ciências sociais seu traço identificador" (González de Gomez, 2000, p. 6), como um "sintoma das mudanças em curso que afetariam a produção e direção do conhecimento no 0 cidente" (González de Gomez, 2000, p. 2). É, a partir de então, que podemos nos referir aos "fundamentos sociais da informação". Contudo, uma questão relevante é: De qual ramo das ciências sociais a ciência da informação se aproxima no primeiro momento? Q ue teorias sociais, conceitos e métodos alimentam a ciência da informação em sua inscrição nas ciências sociais? E como se dá a evolução dessa inserção? Para que se possa responder a essas perguntas, elaboramos, a seguir, um sucinto panorama da evolução teórica das ciências sociais.

\section{A EVOLUÇÃO DAS CIÊNCIAS SOCIAIS: TRÊS MODELOS}

Embora o pensamento e a ref lexão sobre a realidade social e as relações sociais tenha sido uma constante na história da humanidade, desde a Grécia Clássica, passando pela Idade M édia e durante 0 Renascimento, é apenas no século XIX que se torna possível falar em "ciências sociais", pois é o conjunto de reflexões desse período que, incorporando os princípios baconianos e o método cartesiano, vai consistir na forma de conhecimento historicamente conhecida como "ciência moderna".

Se o século XVIII conheceu importantes pensadores da sociedade, como M ontesquieu, Locke, H ume e Rousseau, é com Auguste Comte que, normalmente, identifica-se o início das ciências sociais. Comte, pensador francês conhecido como o pai do Positivismo, propôs a realização de estudos sobre a sociedade com o máximo de objetividade, em busca de leis universais que regessem 0 comportamento da vida social em toda parte. Sua teoria, também denominada Física Social, propunha que a sociedade, em toda parte, evolui da mesma maneira e no mesmo sentido. E, assim, propôs a sua Lei dos Três Estados, segundo a qual toda sociedade evolui de um estado teológico ou fictício para um estado metafísico ou abstrato e, daí, finalmente, para um estado positivo ou científico (Lakatos \& M arconi, 1999, p. 45-46).

A Física Social de Comte fornece a fundamentação teórica para um processo que já vinha acontecendo na Europa dois séculos antes, processo pelo qual "o cálculo de probabilidades, cujas bases são lançadas por Pascal e H uyghes por volta de 1660, torna-se uma nova forma de objetivação das sociedades humanas" (M attelart, 2002, p. 18). Em seu esteio desenvolve-se a sociologia matemática do belga Adolphe Q uételet, as teorias probabilísticas, a aplicação da estatística na gestão das sociedades e a antropometria de Alphonse Bertillon.

Em uma direção apenas parcialmente distinta, já que sua influência direta vem do trabalho de Darwin sobre a evolução das espécies, 0 inglês Herbert Spencer inicia, na mesma época, a Biologia Social (Lakatos \& M arconi, 


\section{A ciência da informação como ciência social}

1999, p. 47). A partir das reflexões sobre a divisão do trabalho (Smith \& Stuart M ill), dos modelos dos fluxos materiais nos agrupamentos sociais (Q uesnay, Babbage) e da teorização sobre as redes (Saint-Simon), Spencer elabora seu modelo organísmico de compreensão da realidade social, promovendo uma analogia entre a sociedade e um organismo vivo, com as partes desempenhando funções para o bom funcionamento do todo.

Entre os vários impactos provocados por esse modelo teórico está a fundamentação da doutrina do $D$ arwinismo Social, que justificou a ação colonizadora européia no século XIX na África e na Ásia, a elaboração da Psicologia das M ultidões (Sighele, Le Bon) e a utilização, nas ciências sociais, de diversos termos e conceitos "tomados de empréstimo" junto à biologia (isolamento, contato, cooperação, competição e outros).

A síntese entre as duas teorizações pioneiras e sua sistematização em um corpo de conhecimentos propriamente "sociológico" foram realizadas por Émile Durkheim, "francês, considerado por muitos estudiosos o fundador da sociologia como ciência independente das demais ciências sociais" (Lakatos \& M arconi, 1999, p. 48). Sua proposta, de considerar os fatos sociais como "coisas", e um empirismo radical estão em perfeita sintonia com o espírito positivista. Sua idéia de "sociedades primitivas" e "sociedades complexas" retoma tanto elementos da Lei dos Três Estados, quanto da perspectiva biológica de Spencer, a qual não é tomada sem críticas. Seu clássico estudo sobre o suicídio é a aplicação das regras do método sociológico por ele definidas dois anos antes: a exclusão de causas individuais e psicológicas, a busca das causas propriamente sociais, a elaboração de leis, a quantificação. Com Durkheim, inaugura-se a Sociologia Funcionalista, também conhecida como Teoria da Integração, que vê a sociedade como um todo formado por partes constituintes diferenciadas e interdependentes. 0 estudo da sociedade sempre deve ser realizado do ponto de vista das funções de suas unidades.

No século $X X$, a Sociologia Funcionalista vai se desenvolver e ser 0 "programa-forte" das ciências sociais, principalmente com os trabalhos de Talcott Parsons (U niversidade de Harvard), Robert M erton e Paul Lazarsfeld (U niversidade de Colúmbia), inspirando as demais ciências sociais, como a antropologia, a ciência política e a comunicação. Essa é a natureza dos cursos superiores de sociologia estruturados ao longo do século, a natureza das primeiras associações profissionais e 0 tipo de pesquisas financiadas pelas grandes fundações e agências governamentais.
A primeira grande cisão vivida no âmbito das ciências sociais tem origem na dialética hegeliana, retomada por $M$ arx para a compreensão da realidade social ( $D$ emo, 1989 , p. 88). A plicado à vida social, o pensamento dialético, que opera com a unidade de contrários, vê a vida social a partir do pressuposto do conflito social, percebendo que "toda formação social é suficientemente contraditória, para ser historicamente superável" (D emo, 1989, p. 89-90). Também conhecida como Teoria do Conflito, a perspectiva marxista consiste no primeiro modelo realmente próprio das ciências sociais - já que o funcionalismo tem seus conceitos e métodos tomados de empréstimo à física e à biologia -, ainda que tenha sido construído em uma aproximação com a filosofia.

Essa segunda abordagem das ciências sociais coloca para 0 campo toda uma gama de novos conceitos e objetos a serem estudados: dominação, ideologia, alienação, reificação. Sua aplicação, ao longo do século XX, vai se dar na construção de diferentes perspectivas: a Teoria Crítica da Escola de Frankfurt, a Teoria da Dependência, a Teoria do Imperialismo Cultural, a Teoria Política Gramsciana, e, mesmo nos Estados $U$ nidos, tem nas formulações de W right M ills um simpatizante da postura "crítica" em oposição à "sociologia de burocrata ou de funcionário da inteligência", isto é, às ciências sociais positivistas e funcionalistas (M attelart, M attelart, 1999, p. 55).

0 estruturalismo, que costuma ser identificado muitas vezes como uma terceira abordagem das ciências sociais (D emo, 1989, p. 171) pode, na verdade, ser compreendido como uma perspectiva específica que, na verdade, constitui manifestações tanto do funcionalismo quanto do marxismo, como podem exemplificar os trabalhos de $M$ anilowski, Radcliffe-Brown e mesmo o "estruturalfuncionalismo" de Parsons, no primeiro caso, ou os trabalhos de Levi-Strauss \& Althusser, no segundo.

A segunda cisão no âmbito das ciências sociais ocorre a partir da fusão dos trabalhos de dois outros precursores das ciências sociais - M ax W eber e Georg Simmel ambos alemães. W eber é tido como o fundador da Sociologia Interpretativa ou Sociologia Compreensiva, na medida em que formula o conceito de ação social, que é a ação do indivíduo dotada de significado para ele - no que difere radicalmente do conceito de fato social em Durkheim. Sua obra sobre a ética protestante e o espírito do capitalismo busca explicar o desenvolvimento do capitalismo nos Estados U nidos, não a partir da idéia de progresso linear das sociedades ou das funções de cada parte no todo (funcionalismo) ou das condições materiais, econômicas, ou do conflito de classes originado pela distribuição dos modos de produção 


\section{Carlos Alberto Ávila A raújo}

(marxismo), mas a partir do "espírito do capitalismo", isto é, do ethos, da atmosfera de valores de uma determinada população, das crenças e significados atribuídos às suas ações.

Já Simmel, em outra direção, vai propor o estudo das relações sociais a partir das pequenas interações cotidianas, originando um campo conhecido por microssociologia. A importância de seus trabalhos vai se dar principalmente no início do século, com as pesquisas da Escola de Chicago. Um de seus representantes, Robert Ezra Park, toma a cidade como "laboratório social", instalando um método de estudo em que os sujeitos não podem ser estudados fora de seu ambiente. Ernest Burgess, na mesma linha, realiza trabalhos em "ecologia social" a partir de uma perspectiva etnográfica.

A primeira grande tentativa de síntese entre as duas possibilidades de compreensão da realidade social (o enfoque na dimensão micro e na atitude interpretativa dos sujeitos) foi conseguida pelo Interacionismo Simbólico, corrente que agregou pesquisadores de diferentes escolas que têm como precursor George $\mathrm{H}$ erbert $\mathrm{M}$ ead. $\mathrm{U} \mathrm{m}$ de seus alunos, $\mathrm{H}$ erbert Blumer, cria o termo em 1937, publicando em 1969 seus três pressupostos básicos: o comportamento humano fundamenta-se nos significados do mundo; a fonte dos significados é a interação social; a utilização dos significados ocorre por meio de um processo de interpretação (Blumer, 1980).

A fenomenologia, corrente de pensamento também inspirada em Simmel, vai ser retrabalhada por Alfred Schut e, a seguir, consistir na fundamentação da sociologia do conhecimento, que tem, no trabalho de Berger \& Luckmann de 1966 sobre a construção social da realidade, seu marco fundamental: a realidade social é vista não só como um processo de construção, apresentando-se como realidade objetiva para os sujeitos, porém construída e reconstruída subjetivamente, ou melhor, intersubjetivamente, no contexto de infinitas interações cotidianas, mas também de processos de institucionalização e socialização (Berger \& Luckmann, 1985).

Ainda uma outra corrente, nessa mesma linha, é a etnometodologia, disciplina fundada por $\mathrm{H}$ arold $\mathrm{G}$ arfinkel em 1967, que tem por objetivo tentar compreender como os indivíduos vêem, descrevem e propõem, em conjunto, uma definição das situações diante das quais se encontram (Coulon, 1995). Por sua proposta, provocou grande polêmica contra a sociologia tradicional, por criticar a idéia de fato social como algo estável e objetivo, propondo uma visão em que esse seja compreendido como produto da contínua atividade dos homens. Dando início a todo um ramo de estudos, difundiu-se primeiro na $U$ niversidade da Califórnia (Sudnow, Schegloff, Zimmerman), depois pelos Estados U nidos (Cicourel), Inglaterra (H eritage) e França (Fornel, O gien).

Se até os anos 70 as ciências sociais se viram no embate entre perspectivas "administrativas" e "críticas" (Horkheimer, 1983), ou diante da oposição en tre "apocalípticos" e "integrados" (Eco, 1985), data dessa época a influência cada vez mais crescente das correntes interpretativas e microssociológicas. Todo esse movimento tem provocado, a partir dos anos 80, uma tentativa de síntese entre as diferentes perspectivas, suas propostas e seus conceitos. Exemplos desse trabalho são a Teoria da A ção Comunicativa de Jürgen $\mathrm{H}$ abermas, 0 M odelo Praxiológico de Louis Q uéré e Pierre Bourdieu, a Sociologia Ref lexiva de Anthony Giddens, Scott Lash e U Irich Beck, a Sociologia do Cotidiano de Michel de Certeau e Michel M affesoli, os Estudos Culturais descendentes da Escola de Birmingham e que têm hoje em Stuart Hall, D ouglas Kellner e Fredric Jameson seus principais representantes, as propostas de ligação com a hermenêutica de Clifford G eertz, entre outros.

\section{A INSERÇÃO DA CIÊNCIA DA INFORMAÇÃO NAS CIÊNCIAS SOCIAIS}

U ma vez apresentados os três grandes modelos teóricos das ciências sociais, torna-se possível identificar que, logo no início, a ciência da informação aproxima-se exatamente do modelo positivista e funcionalista. Como já vinha de uma formalização muito próxima à das ciências exatas, a ciência da informação encontrou, exatamente naquele conjunto de ciências sociais também próximas às ciências exatas, maior identidade de propostas e métodos.

A ssim, os primeiros estudos em ciência da informação já como ciência social estudam a realidade social de uma perspectiva estatística, quantitativa. A utilização de sociogramas para mapeamento dos fluxos de informação, a aplicação de questionários a grandes amostras de usuários e a busca de invariantes cognitivos para a construção de sistemas de informação são alguns exemplos dessa abordagem.

M as, ainda na década de 70, a ciência da informação inaugura uma discussão sobre a especificidade da ciência social (tal como a ciência social como um todo realizou, ainda na época da apropriação dos princípios filosóficos da dialética), sob o referencial teórico marxista: 


\section{A ciência da informação como ciência social}

"Tendo como pressuposto básico e fundamental (...) que a realidade está permanentemente em movimento e em construção, e que todo processo de conhecimento é apenas uma possibilidade, den tre outras, de aproximação da verdade, consideramos que o objeto de estudo da área de informação social deve ser apropriado tendo como referência:

a) A historicidade dos sujeitos cognoscentes e dos objetos cognoscíveis (lembrando que nas ciências do homem são também sujeitos, por definição) que os coloca em uma relação culturalmente determinada; (...) b) A totalidade dos fenômenos sociais; (...) c) A tensionalidade constante que está presente na sociedade (...)" (C ardoso, 1994, p. 111-112).

Estão aí os elementos da perspectiva crítica: a historicidade como condição para a explicação dos fenômenos, 0 conf lito, a inserção de todo fato isolado no contexto global de relações de luta por poder. N umerosos são os exemplos de estudos realizados nesta perspectiva: informação e cidadania, ação cultural, exclusão informacional, informação rural, processos de leitura - chegando até a preocupações atuais relacionadas aos dilemas da sociedade da informação, da revolução tecnológica e da globalização (que não deixaram de se preocupar com a democratização da informação, as condições de acesso, a exclusão).

Contudo, a forma como se deu essa discussão parecia delinear mais uma subárea dentro da ciência da informação (a área de "informação social") do que, propriamente, reformular a forma como a ciência da informação, como um todo, compreende e estuda seu objeto de estudo. A té então, pois, a dimensão "social" da informação aparecia em trabalhos com temáticas específicas (aquelas relacionadas à cidadania, à exclusão, ao popular), convivendo com uma outra parte da ciência da informação debruçada sobre o funcionamento de sistemas de recuperação de informação, estudos de comunicação científica, gestão da informação, tecnologias da informação, que permanecia "intocada" na aproximação com as ciências sociais.

É, apenas com a aproximação junto ao "terceiro ramo" das ciências sociais, isto é, aos enfoques microssociológicos e interpretativos, que a ciência da informação vai conhecer uma reformulação mais profunda de seus pressupostos, que vai alterar sobretudo o significado do que é entendido como "informação".

U m suporte teórico fundamental nesse movimento é exatamente 0 trabalho de Berger \& Luckmann. Ao discutir a realidade como algo que é construído socialmente e não com uma existência em si mesma, independentemente dos sujeitos que conhecem, os autores abrem caminho para uma compreensão da informação não como um dado, uma coisa que teria um significado e uma importância per se, mas como um processo, como algo que vai ser percebido e compreendido de variadas formas de acordo com os sujeitos que estão em relação - o que vai na contramão tanto da definição de Borko (1968) sobre o comportamento e o fluxo da informação excluindo os sujeitos, quanto da definição de Buckland (1991), que vê "a informação como coisa".

A questão da intersubjetividade conformada a partir da informação se torna central para a compreensão dos diferentes planos de realidade, da distinção entre as diferentes formas de conhecimento e dos mecanismos de sua configuração e legitimação. O s sujeitos precisam, necessariamente, ser incluídos nos estudos sobre a informação e, sobretudo, precisam ser incluídos em suas interações cotidianas, formas de expressão e linguagem, ritos e processos sociais. A ciência da informação não pode, assim, jamais, conceber seu processo de criação de sistemas de informação da mesma forma, e processase, assim,

"the shift with in the last approximately 10 years from a technical-system-oriented view towards a more user/ human oriented view (...) including the cognitive approach and approachesfor new system characteristics based on observations of humans" (W ersig, 1993, p. 229)*.

Diversos estudos contemporâneos podem ser apresentados como exemplos da incorporação destas questões no âmbito da ciência da informação, não mais como a constituição de uma linha de pesquisa distinta, mas como uma reformulação na compreensão do objeto de estudo da ciência da informação como um todo. D entre essas perspectivas, destacam-sea abordagem do sen semaking in augurada por Dervin, A twood \& Palmour, entreoutros, os estudos sobre os valores dos usuários originados com M acM ullin \& Taylor, os estudos de natureza cognitiva inspirados na teoria de $M$ aturana \& Varela, a abordagem hermenêutica da ciência da informação desenvolvida por, entre outros, Capurro, os estudos sobre redes de informação com base no referencial teórico de Bourdieu, a incorporação, pelos estudos bibliométricos e de comunicação científica, de contribuições da Arqueologia do Saber de Foucault e da Sociologia da Ciência (Latour, Knorr-C etina e outros).

\footnotetext{
* A mudança, aproximadamente nos últimos dez anos, de uma visão do sistema orientada para a técnica em direção a uma visão mais orientada para o usuário/humano (...) incluindo a abordagem cognitiva e abordagens para novas características dos sistemas baseadas na observação de humanos (tradução do autor).
} 


\section{Carlos Alberto Ávila A raújo}

\section{UMA CIÊNCIA PÓS-MODERNA?}

U ma questão complementar à discussão empreendida até aqui diz respeito à existência de uma outra tensão existente no campo da ciência da informação. Como já apresentado, ela surge em um momento em que já se observam as críticas e o início da crise que se abate sobre o modelo moderno de cientificidade. Assim, podese perceber, na evolução da ciência da informação, a tentativa de consolidação de uma disciplina nos moldes das disciplinas científicas resultantes do processo de construção da ciência moderna. Além disso, é possível visualizar sinais de que a ciência da informação, ainda bem no seu início, tentava constituir-se nos moldes da "ciência pós-moderna".

A "ciência pós-moderna" (Santos, 1996) é entendida como o movimento de superação da crise do paradigma científico dominante desde o século XVII, pela superação do modelo de racionalidade cartesiana, de separação do sujeito e do objeto, a busca da ordem, a separabilidade dos elementos constituintes da realidade, movimento esse motivado pelas crises geradas com a evolução e a aplicação do conhecimento científico, tais como as guerras, os regimes totalitários, a poluição e os desastres ecológicos, a exclusão do acesso ao conhecimento, reforço das desigualdades socioeconômicas, a sofisticação dos instrumentos de dominação (A dorno, Horkheimer, 1990). Fazem parte desse movimento de construção de uma "nova ciência" (Santos, 1996, p. 23-35) as contribuições de Einstein (Teoria da Relatividade), da mecânica quântica (H eisenberg \& Bohr), de Godel (Teorema da Incompletude) e de Prigogine (ordem através das flutuações). 0 utras perspectivas que aí se incluem (Christóvão \& Braga, 1997, p. 35-39) são a Teoria do Caos (Lorenz, Stewart e muitos outros) e a Teoria da Autopoiese (M aturana e Varela). No caso da ciência da informação, a característica mais importante que marca sua postura como uma ciência pós-moderna é a aceitação de sua natureza interdisciplinar em essência:

"Constitui-se assim sua interdisciplinaridade, característica cada vez mais presente como componente da Ciência na sociedade atual, em que a magnitude dos problemas enfrentados (ecológicos, étnicos, demográficos) está a exigir soluções inovativas e plurais. A ciência da informação vem se consolidando, então, a partir de elementos emprestados da matemática, da física, da biologia, da psicologia, da sociologia, da antropologia, da semiologia e da teoria da comunicação e de quantas ciências puderem contribuir para sua fundamentação e aplicabilidade" (Cardoso, 1996, p. 74).
Pode-se notar, aqui, novamente, um movimento de aproximação com as ciências exatas e biológicas, mas em um contexto diferente: não mais na apropriação de conceitos e realização de analogias para a estruturação de um campo disciplinar próprio, mas na busca da contribuição de novos conhecimentos em um movimento inter e mesmo transdisciplinar, no contexto do pensamento complexo, de "religação dos saberes" (M orin, 1987 e 2001).

Além disso, esse movimento é marcado por uma nova conceitualização do que é ciência e da natureza do saber científico diante de sua própria evolução. Como observa W ersig,

"such a science would beestablished as a prototype of a new or postmodern science. Postmodern science is not like classical science, driven by the search for complete understanding of how the world works, but by theneed to develop strategies to solve in particular thoseproblems which havebeen caused by classical sciences and technologies" (W ersig, 1993, p. 229)*.

Essa nova concepção de ciência estaria, assim, na origem mesma da construção do campo da ciência da informação, já que "information science is not to be looked at as a classical discipline, but as a prototype of the new kind of science" (W ersig, 1993, p. 235) (** $^{*}$, embora esse movimento pareça ser distinto daquele da ciência da informação em direção às ciências sociais (particularmente ao que foi definido anteriormente como o "terceiro ramo", que não só ampliou o escopo de atuação da ciência da informação, mas também transformou a forma como esta concebe e estuda seu objeto), na verdade ambos representam as duas faces de um mesmo processo: 0 da superação tanto da tradição da ciência moderna quanto de sua manifestação no campo das ciências sociais. M ais do que isso: é, por pretender se aproximar da "ciência pós-moderna", superando os limites do modelo até então dominante, buscando superar seus impasses metodológicos simplificadores e abarcar um pensamento pautado pela complexidade, que a ciência da informação evolui para novas etapas de diálogo e inserção nas ciências sociais.

A reflexão sobre a evolução da ciência da informação, suas relações com as ciências sociais e com 0 modelo

\footnotetext{
* Tal ciência seria estabelecida como um protótipo de uma ciência nova ou pós-moderna. A ciência pós-moderna não é como as ciências clássicas, dirigidas para a busca do completo entendimento de como o mundo funciona, mas para a necessidade de desenvolver estratégias para resolver em particular aqueles problemas que foram causados pelas ciências e tecnologias clássicas (tradução do autor).

** Ciência da informação não deve ser parecida com uma disciplina clássica, mas com um protótipo de um novo tipo de ciência (tradução do autor).
} 


\section{A ciência da informação como ciência social}

moderno da ciência como um todo, é fundamental para a realização de pesquisas nessa área que efetivamente incorporem todo o avanço acumulado nesse processo e que não apenas fiquem no discurso de uma mudança paradigmática, sem concretamente realizá-la. É sobre esses tópicos, principalmente, que qualquer discussão sobre os fundamentos sociais da informação deve se deter, de forma a contribuir para uma ciência da informação que assuma, então, de forma definitiva, tanto sua natureza de ciência social quanto sua postura de ciência pósmoderna.

\section{REFERÊN C I A S}

ADORNO, T.; HORKHEIMER, M. O Iluminismo como mistificação das massas. In: COSTA LIM A, Luiz. (0 rg). Teoria da cultura de massa Rio de Janeiro : Paz e Terra, 1990, p. 159-204.

BERGER, P.; LU CKM AN N, T. A construção social da realidade: tratado de sociologia do conhecimento. Petrópolis : Vozes, 1985.

BO RKO , H. Information science: what is this? A merican Documentation, V. $19,3-5,1968$

BLU MER, Herbert. A natureza do interacionismo simbólico. In: M ORTEN SEN , C. D. (0 rg). Teoria da comunicação: textos básicos. São Paulo: M osaico, 1980.

BOU RDIEU, Pierre. Esboço de uma teoria da prática. In: Ortiz, R. (O rg.). Pierre Bourdieu: sociologia. São Paulo : Ática, 1983. p. 46-81.

BRON OWSKI, J. O senso comum da ciência. Belo Horizonte : I tatiaia; São Paulo: Editora da U SP, 1977.

BU CKLAND, M. K. Information as a thing. JASIS, v. 42, n. 5, p. 351 360, June 1991.

CARDOSO, Ana Maria Pereira. Retomando possibilidades conceituais: uma contribuição à sistematização do campo da informação social. Revista da Escola de Biblioteconomia da U FM G, Belo Horizonte, v. 23, n. 2, p. 107-114, jul./ dez. 1994.

CARD OSO, A na M aria Pereira. Pós-M odernidade e informação: conceitos complementares? Perspectivas em Ciência da Informação, Belo H orizonte v. 1, n. 1, p. 63-79, jan./ jul. 1996

CERTEAU, Michel. A invenção do cotidiano. Petrópolis : Vozes, 1994.

CHRIST ÓVÃO, Heloisa; BRAGA, Gilda. Ciência da informação e sociologia do conhecimento científico: a intertematicidade plural. Transinformação, Campinas, v. 9, n. 3, p. 33-45, set./ dez. 1997.

COU LON, Alain. Etnometodologia. Petrópolis : V ozes, 1995.

DEM O, Pedro. M etodologia científica em ciências sociais. São Paulo : Atlas, 1989

DIAS, Eduardo José W ense. 0 específico da ciência da informação In: A Q U IN O, M irian. (O rg.). 0 campo da ciência da informação: gênese conexões e especificidades. João Pessoa : Editora U niversitária, 2002, p. 87-99.

DU RKHEIM , Émile. As formas elementares de vida religiosa: o sistema totêmico na Austrália. São Paulo : Paulinas, 1989

. As regras do método sociológico. São Paulo : Companhia Editora Nacional, 1974

EC O, U mberto. A pocalípticos e integrados. São Paulo : Perspectiva, 1985.

GARFIN KEL, H arold. Studies in ethnomethodology. N ew Jersey: Prentice
H all, 1967.

GEERTZ, Clifford. A interpretação das culturas. Rio de Janeiro Zahar, 1985.

GIDDENS, A. As consequências da modernidade. São Paulo : Edusp, 1991.

GONZÁLEZ DE GÓMEZ, M aria Nélida. M etodologia de pesquisa no campo da ciência da informação. DataG ramaZero - Revista de Ciência da Informação, v. 1, n. 6, dez. 2000.

GRAM SCI, Antonio. Concepção dialética da história. Rio de Janeiro: Civilização Brasileira, 1978.

HABERM AS, Jürgen. Consciência moral eagir comunicativo. Rio deJaneiro : Tempo Brasileiro, 1989

HALL, Stuart. Da diáspora: identidades e mediações culturais. Belo H orizonte: Editora U FM G, 2003.

HORKHEIMER, Max. Teoria tradicional e teoria crítica. In: Os PEN SAD ORES. São Paulo : A bril Cultural, 1983.

KELLNER, Douglas. A cultura da mídia. Bauru : Edusc, 2002.

LAKATOS, Eva Maria; MARCONI, Marina. Sociologia geral. São Paulo : Atlas, 1999

LAZARSFELD, Paul Félix. A sociologia. Lisboa : Bertrand, 1970.

MAFFESO LI, Michel. A conquista do presente. São Paulo : Rocco, 1984.

MAFFESO LI, Michel. 0 tempo das tribos: o declínio do individualismo na sociedade de massa. Rio de Janeiro : Forense U niversitária, 1987.

M ATTELART, Armand. História da sociedade da informação. São Paulo : Loyola, 2001.

; M ATTELART, M ichèle. História das teorias da comunicação. Sã̃o Paulo : Loyola, 1999.

MILLS, C.W. A imaginação sociológica. Rio de Janeiro : Zahar, 1968,

MORIN, E. O método III: o conhecimento do conhecimento. Lisboa: Publicação Europa-A mérica, 1987. . 0 método II: a vida da vida. Porto Alegre : Sulina, 2001.

PARSO N S, Talcott. Sociedades: perspectivas evolutivas e comparativas. São Paulo : Pioneira, 1969.

PIN HEIRO, Lena; LO U REIRO, José. Traçados e limites da ciência da informação. Ciência da informação, Braślia, v. 24, n. 1, jan./abr. 1995, p. $42-53$.

QUERÉ, Louis. D'un modèle épistémologique de la communication à un modèle praxéologique. In: Reseaux, Paris, n. 46-47. mar./abr. 1991 Tradução Vera Lígia W estin e Lúcia Lamounier.

SANTOS, Boaventura de Sousa. Um discurso sobre as ciências. 8. ed. Porto : Afrontamento, 1996.

SILVA, Tomaz Tadeu. (0 rg.). o que é, afinal, estudos culturais? Belo Horizonte : A utêntica, 1999.

WEBER, M ax. Ensaios de sociologia. Rio de Janeiro : Zahar, 1963.

WEBER, M ax. A ética protestante e o espírito do capitalismo. São Paulo: Pioneira, 1981.

WERSIG, Gernot. Information science: the study of postmodern knowledge usage. Information Processing \& M anagement. v. 29, n. 2, p. 229-239, mar. 1993. 